\title{
A RATIONAL CODE FOR REPORTING PATTERNS IN BACTERIOCINE AND BACTERIOPHAGE TYPING
}

\author{
P. URBANO AND V. BoDdI* \\ Institute of Microbiology, University of Florence, Viale Morgagni 48, and * Institute of General \\ Pathology, University of Florence, Viale Morgagni 50, 50134 Florence, Italy
}

IN most typing procedures, bacterial strains yield a pattern of + or - reactions with a fixed set of reference materials. For instance, in Pseudomonas aeruginosa typing, a + sign may indicate that the isolate tested produces pyocines capable of lysing one or more of a set of indicator strains, or is susceptible to lysis by one or more of a set of pyocinogenic strains or of bacteriophages. The complete pattern of reactions is a relatively stable and reproducible characteristic of the isolate tested, and may be used as an epidemiological marker, provided that the reference set of indicator (or producer) strains has been fully detailed and is always arranged in the same order. The complete specification of a pattern is, however, lengthy and cumbersome, and most workers prefer to translate it into some familiar code, using numbers or letters, or both, to specify the patterns encountered.

In the field of $P$. aeruginosa typing, the codification of patterns was initially empirical; authors who developed new typing methods assigned a short tag to each of the patterns they recognised and accorded it the dignity of "type". This served their purpose of concision but had serious drawbacks, in that other workers who followed their methods inevitably came across new patterns and were faced with the problem of coding them. Thus, Darrell and Wahba (1964) used a set of 12 indicator strains and established 11 provisional pyocine types, corresponding with reaction patterns reported in a table and designated by capital letters; strains that gave negative reactions on all 12 indicators were considered untypable. Zabransky and Day (1969) used seven of the Darrell and Wahba indicators, together with four others, and were forced to define eight additional " Mayo types" and four subtypes. More recently, Shriniwas (1974), using eight of Wahba's original indicators, found 154 inhibition patterns; he retained the original letter code for the patterns falling into the Darrell and Wahba types, and assigned a numerical code to 20 other frequently encountered patterns.

With such a reporting procedure a good deal of information is lost; for instance, it is impossible from the published reports to understand which patterns, apart from the most common ones, were in fact present in a sample of isolates. Also, one may not calculate the frequency of positive reactions given by one particular indicator strain, nor assess the discriminatory power of each indicator. Furthermore, identical patterns may well be given different designations by different authors, making it difficult to compare the results even when the same indicators and typing methods have been used.

Epidemiological efficiency dictated the need to enlarge the reference sets in order to obtain highly discriminating patterns for use as markers of individual strains. In current " fingerprinting " methods, over 20 reactions of the tested isolate or its products with reference strains or their products may be used (Farmer and Herman, 1969; Rampling, Whitby and Wildy, 1975), and the number of theoretically possible patterns reaches the millions or tens of millions. Clearly there is need for an unambiguous codification system; such is the one devised by Farmer (1970), by which any possible pattern may be coded without loss of information, so that the type designation may be decoded to yield the full sequence of reaction results. However, in this system, the rules for codification are arbitrary, and one must refer to the published key to break the code. In dealing with pyocin types, it occured to us that simple binary arithmetic may help in reporting patterns, with distinct advantages over the methods previously followed.

Received 14 June 1977; accepted 7 Aug 1977.

J. MED. MICROBIOL.-VOL. 11 (1977) 
Let the typing procedure be the reaction of the isolate with an ordered set of $N$ reference strains, and record each result as 0 if negative and 1 if positive. The sequence of zeros and ones so obtained represents the reaction pattern of the test organism with the reference set used; there are $2^{N}$ different possible patterns, for each of which a simple designation is required. We propose that the whole sequence be considered a binary number and be translated into its decimal counterpart. The "type " designation will then follow the natural series of integers from 0 to $2^{N}-1$.

As an illustration, consider the case of $N=5$, as found in Küchler (1976), who used Govan and Gillies' (1969) sub-set of reference strains A to E. In the table we have arranged into their natural order the 32 possible patterns, along with our suggested designation and with the one adopted by Küchler and partly derived from Govan and Gillies (1969).

When working with small reference sets it may be convenient to follow a graphic method for a quick designation of the patterns (see the figure, for $N=5$ ). When reading the results in their order, start from the common origin and move along the upper segment if the first reaction is negative, along the lower if positive; at each bifurcation move on according to each successive test result, until the pattern number is reached after the $N$ th bifurcation.

With larger reference sets the graphical method becomes impractical. One may then proceed arithmetically, remembering that binary numbers are in fact sums of powers of base 2 , just as decimal numbers are sums of powers of base 10 ; powers are indicated by the

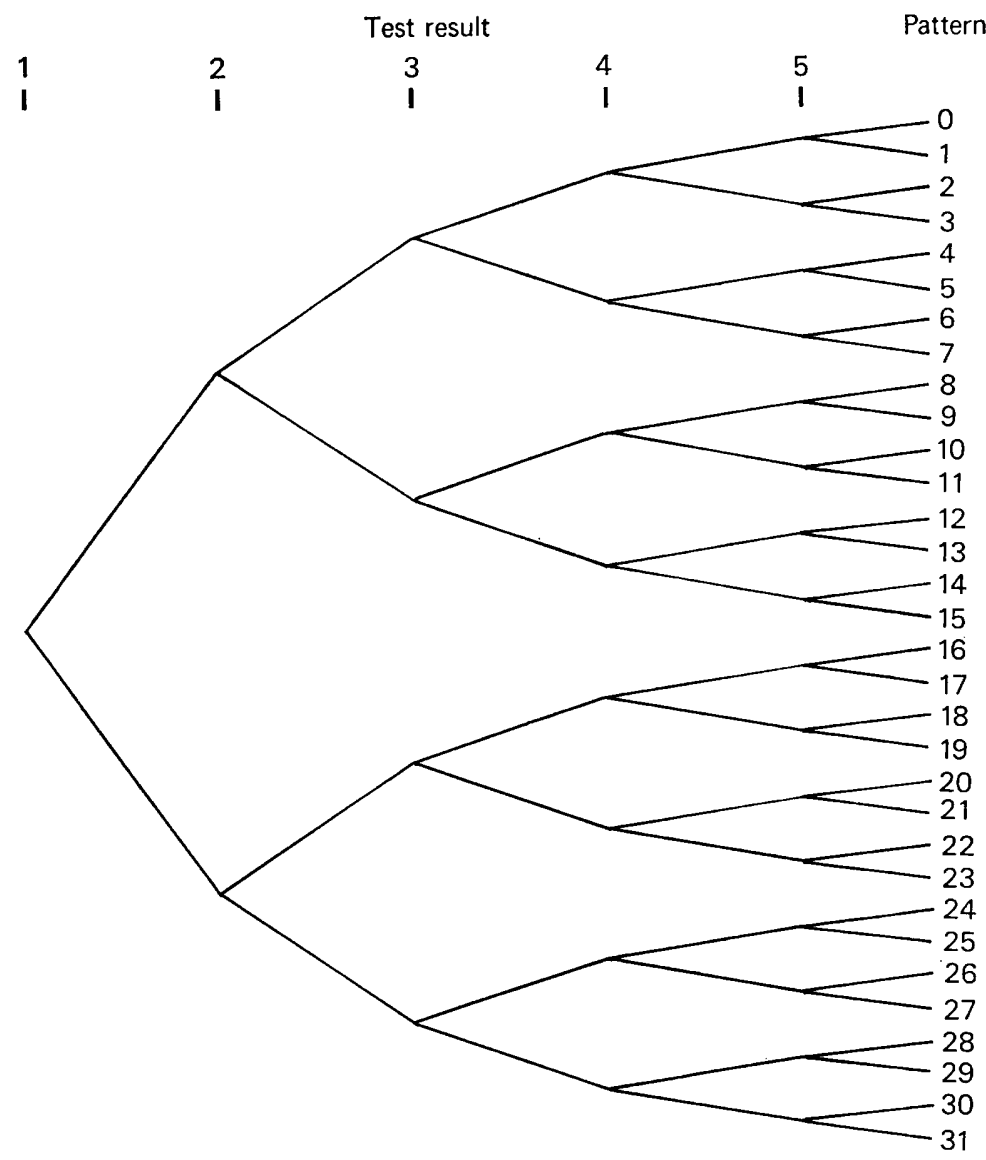

FIGURE.-Graphic method for the designation of typing patterns with a set of five ordered indicators. 
TABLE

The 32 patterns of results obtainable with a battery of five tests. Each pattern may be considered a binary number, and it may be assigned a progressive decimal number, from 0 to $2^{5-1}=31$

\begin{tabular}{|c|c|c|c|c|c|}
\hline \multirow{2}{*}{ Pattern } & \multicolumn{2}{|c|}{ Designation } & \multirow{2}{*}{ Pattern } & \multicolumn{2}{|c|}{ Designation } \\
\hline & Suggested & Original* & & Suggested & Original* \\
\hline 00000 & 0 & $\mathrm{f}$ & 10000 & 16 & 31 \\
\hline 00001 & 1 & 14 & 10001 & 17 & 15 \\
\hline 00010 & 2 & 24 & 10010 & 18 & 23 \\
\hline $\begin{array}{llllll}0 & 0 & 0 & 1 & 1\end{array}$ & 3 & 8 & 10011 & 19 & 7 \\
\hline 00100 & 4 & 28 & 10100 & 20 & 27 \\
\hline $\begin{array}{lllll}0 & 0 & 1 & 0 & 1\end{array}$ & 5 & $\mathrm{~g}$ & 10101 & 21 & 11 \\
\hline 00110 & 6 & 20 & 10110 & 22 & 19 \\
\hline $\begin{array}{lllll}0 & 0 & 1 & 1 & 1\end{array}$ & 7 & $\mathrm{c}$ & 10111 & 23 & $\mathrm{~d}$ \\
\hline $\begin{array}{llllll}0 & 1 & 0 & 0 & 0\end{array}$ & 8 & 32 & 11000 & 24 & 29 \\
\hline $\begin{array}{lllll}0 & 1 & 0 & 0 & 1\end{array}$ & 9 & 16 & 11001 & 25 & 13 \\
\hline $\begin{array}{llllll}0 & 1 & 0 & 1 & 0\end{array}$ & 10 & 22 & 11010 & 26 & 21 \\
\hline 01011 & 11 & $\mathrm{~h}$ & 11011 & 27 & 5 \\
\hline 011100 & 12 & 26 & 11100 & 28 & 25 \\
\hline $\begin{array}{lllll}0 & 1 & 1 & 0 & 1\end{array}$ & 13 & e & 11101 & 29 & 9 \\
\hline $\begin{array}{lllll}0 & 1 & 1 & 1 & 0\end{array}$ & 14 & 18 & 11110 & 30 & 17 \\
\hline $\begin{array}{lllll}0 & 1 & 1 & 1 & 1\end{array}$ & 15 & b & $\begin{array}{lllll}11 & 1 & 1 & 1\end{array}$ & 31 & $\mathrm{a}$ \\
\hline
\end{tabular}

* See Küchler (1976) and text.

position of the digit in the sequence ( 0 for the last, 1 for the next to the last, and so on), the digit itself indicating how many times that power should be summed. Thus, for instance:

$$
10001011=\left(2^{0}+2^{1}+2^{3}+2^{7}\right)=1+2+8+128=139 .
$$

Obviously, the pattern number may be tranformed back to its binary counterpart, which itself represents the whole pattern of results. This may be necessary when one wishes to compare different patterns, and wants to know how many and which test results are different. For instance, patterns no. 0 and 1 in the table differ for just one test result (the last one), while patterns no. 15 and 16 differ for every single test result.

In practice, the detection of similarities and differences among a large number of long patterns requires great computing facilities, for which the binary code is best suited. It is only for reporting purposes that alternative pattern designations may be useful; the one we suggest may easily be done by machine.

Pattern designations should be treated like names attached to bacterial isolates, and care should be taken in their comparison, because their numerical difference may be misleading.

\section{SUMMARY}

Empirical methods of assigning type designations to the patterns that describe the reactions of a bacterial isolate towards a reference set of indicator (or producer) strains have resulted in loss of information and have made it difficult to compare published reports.

We propose that the whole pattern sequence be considered a binary number and be translated into its decimal counterpart, which may be used as a rational, compact and meaningful type designation for reporting purposes.

\section{REFERENCES}

Darrell, J. H. ANd Wahba, A. H. 1964. Pyocine-typing of hospital strains of Pseudomonas pyocyanea. J. clin. Path., 17, 236.

J. MED. MICROBIOL.—VOL. 11 (1977) 
FARMER, J. J. III 1970. Mnemonic for reporting bacteriocin and bacteriophage types. Lancet, $2,96$.

FARMER, J. J. III AND HeRMAN, L. G. 1969. Epidemiological fingerprinting of Pseudomonas aeruginosa by the production of and sensitivity to pyocin and bacteriophage. Appl. Microbiol., 18, 760.

Govan, J. R. W. AND Gillies, R. R. 1969. Further studies in the pyocine typing of Pseudomonas pyocyanea. J. med. Microbiol., $2,17$.

KÜCHLER, R. 1976. Vergleichende Pyocin-Typisierung von Pseudomonas aeruginosa mit verschiedenen Indikatorsätzen. Zentbl. Bakt. ParasitKde, I. Abt. Orig., A234, 202.

Rampling, A., Whitby, J. L. AND Wildy, P. 1975. Pyocin sensitivity testing as a method of typing Pseudomonas aeruginosa: use of "phage free" preparations of pyocin. J. med. Microbiol., 8, 531.

Shriniwas 1974. Aeruginocine typing of Pseudomonas aeruginosa. J. clin. Path., 27, 92.

ZABRANSKY, R. J. AND DAY, F. E. 1969. Pyocine typing of clinical strains of Pseudomonas aeruginosa. Appl. Microbiol., 17, 293. 